\title{
CRECIMIENTO E INSTITUCIONALIZACIÓN DE LA CIENCIA POLÍTICA EN MÉXICO*
}

\author{
Growth and Institutionalization of Mexican Political Science
}

\section{FERNANDO BARRIENTOS DEL MONTE}

Universidad de Guanajuato

\begin{abstract}
RESUMEN
El balance de la ciencia política en México en los primeros tres lustros del siglo XXI muestra una ciencia institucionalizada, con solo observar el número de programas de grado y posgrado, publicaciones, asociaciones e investigadores dedicados a cultivarla. Al mismo tiempo se mantiene su fragmentación interna, propia de la disciplina desde sus orígenes. Todavía no se asume como una ciencia al singular (ciencia política) y se sigue pensando en plural (ciencias políticas); empero la democratización en el país la impactó favorablemente pues abrió un abanico de temas que requieren explicaciones propiamente politológicas, lo que ha impulsado el crecimiento de la disciplina. Comparada con su situación en décadas anteriores, la ciencia política mexicana ha crecido de manera sostenida y se vislumbra un futuro promisorio para su desarrollo.
\end{abstract}

Palabras clave: Ciencia política, México, universidades, investigación, institucionalización.

\begin{abstract}
The balance of Mexican political science in the beginning of the 21st century is positive. The development of the discipline is reflected in the growing number of undergraduate and graduate programs, publications, professional associations and researchers. However, internal fragmentation still persists. The discipline is not yet seen as a singular science (political science), but rather as a plural one (political sciences). Nevertheless, the country's democratization was favorable to the discipline in terms of opening a range of issues that now demand scientific explanations, and this has been reflected in the growth of the field of studies. In comparison with prior decades, Mexican political science has grown steadily and the future is promising for its development.
\end{abstract}

Key words: Political Science, Mexico, Universities, Research, Institutionalization.

* El autor agradece a Carlos Estrada Nava su apoyo con la información sobre los egresados de las carreras de ciencias políticas, a Emmanuel Villagómez León por su colaboración en la revisión del texto, y a los evaluadores de la RCP. 


\section{INTRODUCCIÓN}

La ciencia política en México, como en América Latina, es una ciencia relativamente nueva. Ello no significa que no se enseñara en décadas pasadas, pues basta recordar que en 1951 se funda la Escuela Nacional de Ciencias Políticas y Sociales -hoy facultaden la Universidad Nacional Autónoma de México (UNAM), y subsecuentemente en los siguientes lustros se difuminó la disciplina de manera lenta en otras universidades estatales y privadas. Su carácter "novedoso" radica en que es a partir de los años ochenta del siglo XX que empieza a adquirir autonomía y afirmarse como tal, una vez que fue abandonando los paradigmas sociológicos (principalmente el marxismo) que la habían colonizado en los años sesenta y setenta. Décadas atrás tuvo la impronta jurídicoinstitucionalista que la influyó desde su nacimiento. Al rastrear sus orígenes, incluso desde el siglo XIX (vid. Meyer y Camacho, 1979), se puede observar que en México como en otras latitudes se transitó lentamente de las "ciencias políticas", en plural, a la "ciencia política", en singular. Esta última es la más joven. En las ciencias políticas, influencia de las universidades europeo continentales, se conjuntaban disciplinas que iban desde la filosofía, la historia de las ideas, el derecho constitucional, la teoría del Estado, las "ciencias diplomáticas", incluso la sociología política, mientras que en la ciencia política se concentran las áreas de estudio de la política empírica en cinco grandes campos: la política comparada, las relaciones internacionales, la administración pública, la comunicación política y la teoría política (Caramani, 2008: 2-3). La ciencia política "al singular" no se observa claramente en México, pues poco se ha avanzado en interiorizar el método de la comparación (cfr. Rivera y Salazar, 2011: 88). Se puede decir que existe cada vez un uso más difundido de técnicas de análisis empírico cuantitativo y cualitativo que son parte de la comparación, pero esta se ha entendido más como la comparación entre países y no de unidades de análisis y casos de manera diacrónica y sincrónica.

¿Qué se entiende entonces por ciencia política en México? Podemos decir que la ciencia política en México se orienta al estudio de los fenómenos políticos empíricos utilizando diversas perspectivas de análisis que se inclinan hacia el pluralismo. Es decir, se hace ciencia política, pero no se abandona del todo las ciencias políticas. Y ello se puede observar en la denominación misma de las carreras que forman politólogos en México (Alarcón, 2012b: 33). La mayoría de los programas de estudio de grado (o licenciatura) son en administración pública -principalmente-, relaciones internacionales e incluso en derecho y economía, con el apéndice "ciencias políticas", el que se coloca antes o después. Solo en contadas universidades existe la carrera con el rótulo de ciencia política en singular. De manera más específica: existe ciencia política en México porque hay una tradición académica en el estudio de la política ${ }^{1}$ que se enseña en las universidades, desarrolla un conocimiento lógico y estructurado sobre bases empíricas de los fenómenos políticos y exige a quienes la estudian un compromiso con los cánones de las ciencias sociales.

1 Esta situación la notaba Zamitiz (1999: 119) al citar a Stoker (1995: 15), quien señala que en Inglaterra existe cierta incomodidad con el término "ciencia política", prefiriendo términos como: gobierno, política, teoría e instituciones políticas. 
Somit y Tanenhaus (1964) indican que las características de una disciplina consolidada se pueden identificar en: a) una cierta posición mental de sus miembros, manifestada en un consenso sobre métodos y objetivos y en la satisfacción derivada de identificarse con ella; $b$ ) una organización formal en el ámbito de la enseñanza, de las asociaciones y de las publicaciones, y c) una galería compartida de grandes hombres. Un balance de la disciplina implicaría también observar los periodos de ciencia "normal" y las "revoluciones" a la manera de T. Kuhn, y la ciencia política no estaría exenta de caracterizarse por una tensión entre las perspectivas "sacerdotales", "neutrales" y "proféticas" como sucede en la Sociología según Robert Friedrichs (2001).

Al analizar en conjunto el estado actual de la ciencia política en México hay que intentar sortear al menos dos obstáculos, por un lado la dificultad de contar con datos que permitan observar trabajos específicamente politológicos, ya que, como se ha argumentado, al revisar las publicaciones periódicas, en México se sigue entendiendo en gran medida la ciencia política en plural y no tanto en singular. Ello dificulta que se puedan llevar a cabo análisis comparativos al menos en términos cuantitativos como se han elaborado en otras latitudes (v.g. Hix, 2004a y 2004b). También se debe asumir que, como en cualquier país, conviven diversas lógicas y temas de investigación, por lo que un análisis exclusivamente cuantitativo, aún así sea simplemente indicativo, dejaría fuera muchos trabajos que no se ciñen a los cánones de la ciencia política empírica sin dejar de ser por ello científicos.

A principios del siglo XXI, Paul Hirst (2003) señalaba que en el desarrollo de la ciencia política se vislumbraban dos peligros y sobre los cuales habría que poner remedio antes de que fuera demasiado tarde: por un lado, la reideologización de la disciplina y, por otro, la hegemonía de la ciencia política "estilo estadounidense". Sobre la primera, alertaba sobre el dominio de ciertos temas sobre otros debido a influencias externas a la agenda política, cuestión que ya había sucedido en los setenta con el marxismo y en los ochenta con la influencia de la derecha económica, que promovió la adopción de modelos simplificadores de la realidad. Para Hirst, en el contexto de la globalización y la antiglobalización se están reviviendo el idealismo cosmopolita, el neoimperialismo, y la izquierda revolucionaria que fracasaron en el siglo XX y se presentan en el siglo XXI disfrazados bajo una nueva ideología. Por otro lado, hallamos la hegemonía de la ciencia política "estilo estadounidense". Las universidades estadounidenses cuentan con mayores recursos y esto se refleja en sus revistas (journals) que cuentan con amplio prestigio, y gracias a su capacidad de distribución han difundido los sesgos metodológicos de la ciencia política estilo americano que se refleja en sus generalizaciones, y dicha forma de hacer ciencia política está creando una 'mentalidad' sobre el cómo de la disciplina. La excesiva "objetividad" y la preferencia por los métodos estadísticos afecta los problemas analizados, y "ello no es objetividad, es despolitización" (Hirst, 2003: 48). La ciencia política en México no está exenta de la tensión que han generado los debates metodológicos al interior de la ciencia política, pero no existe hasta ahora un ejercicio amplio que muestre los alcances de dicha tensión: no sabemos si realmente ha afectado su desarrollo o en qué medida ha sabido dar respuestas a esta situación. 
Debido a lo anterior, en este texto se desarrolla un balance breve pero actualizado de la ciencia política en México señalando algunos aspectos relevantes: a) la identificación de los miembros que la cultivan, y ello se nota en el creciente interés por elaborar recuentos y autorreflexiones sobre la disciplina; $b$ ) el cambio en los objetos de estudio derivado del proceso de democratización, que amplió el abanico de temas y la necesidad de explicaciones politológicas, y sobre todo; $c$ ) los elementos de la organización formal: matrícula, distribución territorial de las universidades en donde existen programas de grado y posgrado, los investigadores, las publicaciones, así como las asociaciones.

\section{EL CRECIENTE INTERÉS SOBRE LA CIENCIA POLÍTICA EN MÉXICO}

En los tres primeros lustros del siglo XXI se nota un creciente interés por analizar la historia, el desarrollo y el hacer de la ciencia política en México. A diferencia de los estudios de finales del siglo XX, en su mayoría elaborados dentro y por académicos de la Facultad de Ciencias Políticas y Sociales (FCPyS) de la UNAM, ${ }^{2}$ gran parte de los análisis contemporáneos en torno a la ciencia política en México son de origen diverso, y en su conjunto muestran una disciplina consolidada y en crecimiento, pero al mismo tiempo necesitada de una comunidad epistémica más fuerte.

Podemos agruparlos en cuatro vertientes: primero, los estudios e investigaciones que se han centrado en explicar el desarrollo histórico de la ciencia política mexicana influenciada por eventos del contexto interno, es decir, nacional y local; y el impacto de factores exógenos, sobre todo las transformaciones en los sistemas políticos latinoamericanos y los grandes cambios mundiales de finales del siglo XX, al tiempo que absorbe y discute las corrientes dominantes de la disciplina y las adapta a los problemas nacionales (Acosta Silva, 2009; Barrientos, 2012; Vida de la Rosa, 2013; Gutiérrez, 2014; y SuárezIñiguez, 2014a). Segundo, aquellos trabajos dedicados a analizarla en su interior, desde sus orígenes a la par de los programas de estudio (Alarcón Olguín, 2012a, 2012b; Figueroa Franco, 2012), pero también del cómo se hace ciencia política tanto en sus resultados de investigación (Salazar-Elena y Rivera, 2011), así como desde las experiencias que le dan forma a la comunidad académica que la practica (Sánchez Noriega, et. al. 2013) e incluso por la vía de las recomendaciones para ser "un buen politólogo" plasmadas en una serie de cartas a los estudiantes de ciencia política (Cortés y López, 2010 y 2013).

Un tercer grupo son las investigaciones que analizan las trayectorias sobre las principales temáticas que han atraído la mirada de los politólogos mexicanos en los primeros años del siglo XXI, algunos de los cuales se encuentran en el libro La Ciencia Política en México hoy: ¿qué sabemos? (Reveles Vázquez coord., 2012), en el cual se hace un balance de los estudios sobre el presidencialismo (Escamilla Cadena), el parlamentarismo en México

2 En los años noventa del siglo XX y en mayor medida entre 1994 y 1995, en las páginas de la revista Estudios Políticos de la UNAM, se publicaron poco más de 30 artículos, notas y reflexiones que analizaron el estado de la ciencia política, empero centrados en el desarrollo de aquello que se hacía en esa propia universidad y su historia, impulsados sobre todo por un proceso de reforma a los planes de estudio que se concretaron pocos años después. Vid. Singer Sochet, 2013. 
(Béjar Algazi y Cortéz Salinas), las elecciones (Bravo Ahuja), los partidos políticos (Reveles Vázquez), el sindicalismo y el corporativismo (Arrieta Cisneros), las élites y el liderazgo político (Reyes García), la cultura política (Muñoz Patraca) y la ciudadanía y la educación (Cuna Pérez y Alaniz Hernández). En este tenor, sobresale el texto de Flores Mariscal (2012), quien desarrolla un sucinto análisis del desarrollo de los estudios sobre la ciencia política en México, en el cual se constata la madurez de la disciplina y el creciente interés por la autorreflexión.

El cuarto y último grupo son los trabajos que estudian el desarrollo de la ciencia política en diversos estados y universidades de México. Hasta hace algunas décadas, gran parte de la ciencia política en México se desarrollaba en las universidades del centro del país, y específicamente en la Ciudad de México. En otros estados su presencia era magra y endeble, pero precisamente los cambios que trajo consigo el proceso democratizador en las últimas dos décadas del siglo XX (cfr. Loaeza, 2005) impulsaron los estudios políticos y por lo tanto la creación de licenciaturas y posgrados en ciencias políticas, generando una inercia descentralizadora del desarrollo de la disciplina. En este sentido caben los trabajos presentados durante el Coloquio Historia y Balance de la Ciencia Politica en México, celebrado en la Universidad Autónoma de San Luis Potosí (agosto de 2014), en el que se analizó en desarrollo la ciencia política en los estados de Aguascalientes, Jalisco, Nayarit, Puebla y el Distrito Federal, por mencionar. Para el caso de Jalisco en específico sobresale la narración de la experiencia de creación de la otrora Facultad de Estudios Políticos y Gobierno en la Universidad de Guadalajara en 1991, como respuesta a los cambios que sucedían no solo en México, sino en el contexto internacional y que requerían la formación de especialistas en estudios políticos para comprender y actuar en el naciente contexto de la posguerra fría (Gómez, 2011). Los trabajos compilados por Arellano Ríos y García Vázquez en Ciencia Política y Políticas Públicas en Jalisco. Teoría y metodologías (2013) resultan una aportación relevante para las ciencias políticas en México, ya que muestran que las preocupaciones nacionales -las cuales muchas veces se reducen a lo que se dice, hace y escribe en la capital del país- tienen igual relevancia en otros estados y que su discusión pasa por las universidades estatales. Más aún, como señala en otro trabajo Arellano Ríos (2014) para el estado de Jalisco, pero que puede ampliarse a otros, gran parte de la ciencia política en los estados se desarrolla en las universidades públicas y aún hoy los estudios electorales ocupan gran parte de las agendas de investigación.

No está de más detenerse en la obra Testimonios: vida y trayectoria del Centro de Estudios Políticos 1971-2011 (2013), que reúne las voces de veintitrés profesores de la FCPyS de la UNAM quienes repasan los primeros pasos de la formación de la escuela decana de la ciencia política en México; la mayoría de los testimonios destacan la influencia de los primeros cultores de la disciplina en el país, quienes desde posiciones directivas dentro de la universidad fomentaron e impulsaron iniciativas que marcaron los programas de estudio en ciencia política, la investigación y en análisis de la realidad política mexicana. Sobresale que había una dualidad en cómo se estudiaba y se hacía ciencia política durante las décadas de los cincuenta hasta ya entrados los años ochenta: el contexto internacional influía incluso en la metodología; pero las corrientes empiristas de los Estados Unidos se estudiaban poco "por su claro sesgo ideológico en la polaridad de la guerra fría, por su 
alejamiento de los problemas de desigualdad y la explotación, prioritarios en América Latina y por el peso del marxismo que rechazaba al imperialismo norteamericano. En pocas palabras, había mucha actividad política, pero muy poco análisis politológico" (Sánchez-Noriega, 2013: 21). Hoy la realidad es diferente, y ello se nota en la pluralidad de temas que se tratan desde variadas perspectivas en muchas universidades y centros de investigación en México.

\section{DE LAS PERSPECTIVAS HEGEMÓNICAS AL PLURALISMO}

En los primeros tres lustros del siglo XXI se observan numerosos enfoques teóricos y uso de perspectivas metodológicas diversas -más bien eclécticas- en el análisis de la política mexicana. Si en las décadas anteriores se podían vislumbrar ciertas tendencias teóricas hegemónicas como el institucionalismo clásico y luego perspectivas sociológicas en especial el marxismo y el funcionalismo, los cambios que trajo consigo el proceso de democratización impactaron las ciencias sociales, y la ciencia política en específico se orientó a tratar de comprender la democracia y sus actores en un contexto postautoritario. En pocas palabras, son los temas y no la perspectiva teórica la que orienta la ciencia política mexicana.

Los temas que han dominado la agenda politológica en México son en gran medida los relacionados con los asuntos electorales y el sistema de partidos. Ello se explica por el tipo de transición a la democracia por medio de sucesivas reformas electorales a nivel constitucional -más de 12 desde 1986 hasta 2013- que fueron permitiendo disminuir por esta vía el poder del otrora partido hegemónico, el Partido Revolucionario Institucional (PRI). Allí se enmarcan los intentos por comprender el lento proceso de democratización y escudriñar los eventos desde los años setenta del siglo XX, hasta las últimas reformas de 2013. Si en el contexto del autoritarismo destacaba una ciencia política que trataba de explicar el sistema político mexicano estudiando la "ideología de la revolución", el corporativismo, el presidencialismo, entre otros temas, y con una preferencia a "narrar" los procesos como forma de explicación; en el contexto de la democracia (débil, por cierto), la ciencia política se encontró con una situación pluritemática en la que los partidos políticos, como actores centrales de la democracia, requerían ser analizados desde su interior, sus élites, la selección de sus candidatos y sus estrategias de competencia. El pluralismo se observa en la conformación del Congreso de la Unión, que a partir de 1997, principalmente en la Cámara de Diputados, inició una era de gobiernos sin mayoría absoluta que perdura hasta la fecha (Casar y Marván, 2014: 28-29). Ello cambió las estrategias de los partidos al interior de las cámaras y en los gobiernos estatales (subnacionales), generando escenarios políticos que difieren territorialmente: en algunas regiones predominan unos partidos sobre otros.

Evidentemente los cambios más significativos fueron por un lado la democratización de la capital del país con las primeras elecciones democráticas en la Ciudad de México en 1997 y la conclusión de la transición política al ganar el Partido Acción Nacional (PAN) la presidencia de la república en el año 2000. Estos cambios ofrecieron resultados paradójicos 
y casi diametralmente opuestos: por un lado la transparencia y la confiabilidad en los procesos electorales, pero por otro lado una incapacidad institucional en ofrecer soluciones democráticas a los problemas contemporáneos. Estos procesos impactaron el quehacer de una gran parte de los politólogos, quienes se han volcado en gran medida a analizar las insuficiencias del sistema electoral y las posibles líneas que las reformas subsecuentes deberían contemplar, al grado que la figura de politólogo se llegó a mimetizar en los círculos de la opinión pública con "electorólogo", un neologismo (quizá) propio de los sistemas políticos que no terminan de concretar un sistema electoral (asignación de escaños, administración y contencioso electoral) eficiente. Naturalmente las reformas al sistema electoral y de partidos permitió que la agenda política se ampliara, que nuevas reformas impactaran el sistema político mexicano y por tanto la ciencia política mexicana mirara hacia espacios y actores que en décadas pasadas eran residuales en el estudio de la política. Un ejemplo de ello es la introducción de los análisis sobre el poder judicial (o judicial politics), el cual había estado hegemonizado por el derecho. Pero el (nuevo) rol que han asumido los jueces y las cortes en la determinación del equilibrio de poder, el déficit del Estado de derecho, la ineficiencia de los ministerios públicos (Aguiar, 2012), y sobre todo la judicialización de la política han abierto la necesidad de desarrollar análisis en los cuales se observe la dimensión política del actuar de las instituciones de justicia, como factores que impactan la legitimidad del sistema político (por ejemplo los trabajos en: Vázquez, 2012).

Igualmente el área que ha requerido mayor atención es el poder legislativo, más allá de su conformación. Todavía en 1999 se notaba una escasez de estudios politológicos en torno al poder legislativo, dominado por los análisis provenientes del ámbito jurídico (Lujambio, 1999), una situación que ha cambiado radicalmente tres lustros después, observándose no solo un creciente número de estudios en torno al poder legislativo nacional, sino también los congresos locales, en los cuales ya no se trata solo de analizar la relación ejecutivo-legislativo, sino también el trabajo interno desde las comisiones, el sistema de pesos y contrapesos, la rendición de cuentas, el proceso presupuestal y gasto público, así como la evolución o profesionalización del trabajo legislativo (Patrón, 2014). Igualmente la ciencia política mexicana se ha abocado al análisis de los organismos constitucionales autónomos que han modificado la fisonomía de la tradicional división de poderes, como el rol del banco central, las comisiones de derechos humanos, los institutos electorales nacionales y locales, los órganos de transparencia y de rendición de cuentas, entre otros; aunque se debe señalar que gran parte de los estudios sobre estas instituciones provienen de las perspectivas jurídicas, lo que es un área de oportunidad para los politólogos mexicanos contemporáneos. Derivado de las transformaciones en el sistema político, algunos de los temas que han sido -relativamente- abandonados son el estudio del sindicalismo y el corporativismo, pues estos ya no son piezas centrales como sucedió en décadas pasadas (Arrieta, 2012), e igualmente el estudio de las élites y el liderazgo político, que sigue concentrándose en pocos estudiosos (v.g. Ai Camp), pero que requiere mayor énfasis sobre todo con relación al análisis de la circulación de las élites en el contexto de la alternancia política tanto a nivel nacional como local. 


\section{LA FORMACIÓN DE POLITÓLOGOS EN MÉXICO}

Mientras en 1970 solo existían cuatro universidades en las cuales se ofrecía la formación en ciencias políticas (UNAM, Universidad Autónoma de Baja California, la Universidad Iberoamericana y la Universidad Autónoma de Ciudad Juárez), para el 2013, según el Anuario estadístico de la Asociación Nacional de Universidades e Instituciones de Educación Superior A.C. (ANUIES), en 84 universidades se ofrecen carreras con el rótulo "ciencias políticas". Ello, como ya se señaló anteriormente, porque la carrera de ciencia política (al singular) existe solo en muy pocas universidades. Respecto de la distribución de la matrícula (Cuadro 1), si bien el número de universidades privadas con estas carreras es superior (51), lo cierto es que en su mayoría son pequeñas escuelas. De allí que el grueso de la matrícula se concentre por lo general en universidades e instituciones públicas. Es una carrera que poco a poco va ganando presencia nacional, pues en universidades públicas está presente en 24 estados, mientras que en universidades privadas en 17 estados.

Cuadro 1. Universidades e instituciones que ofrecen licenciatura en ciencias políticas en México, 2015

\begin{tabular}{lccccc}
\hline \multirow{2}{*}{ Tipo } & \multirow{2}{*}{ Número } & \multirow{2}{*}{ Estados } & \multicolumn{3}{c}{ Matrícula } \\
\cline { 4 - 6 } & & & Hombres & Mujeres & Total \\
\hline Universidades Públicas & 33 & 24 & 7.999 & 7.050 & 15.049 \\
Universidades Privadas & 51 & 17 & 1.266 & 841 & 2.106 \\
Total & 84 & - & 9.265 & 9.981 & 17.155 \\
\hline
\end{tabular}

Fuente: Elaboración propia con datos del "Anuario estadístico 2013", Asociación Nacional de Universidades e Instituciones de Educación Superior, 2015 <http://www.anuies.mx/content. php?varSectionID=166> [consultado en enero 2015]

Destaca la distribución por sexo que, guardando las proporciones, muestra una tendencia a la paridad entre hombres y mujeres que desean estudiar estas licenciaturas. Dicha cuestión está tratada en un estudio elaborado por Roqueñí (2014), quien desarrolla un análisis del acceso y permanencia en la carrera en relación con la paridad de género. Subraya que en las universidades públicas hay mayores posibilidades de ingreso para las mujeres en esa licenciatura en relación con las universidades privadas. Si bien las mujeres, en términos generales, son las que más presentan solicitudes de ingreso también son las que menos logran el acceso, como consecuencia, la matrícula femenina en esta licenciatura es menor respecto de la masculina, con excepción en las Universidades públicas estatales, donde la tendencia es favorable hacia las mujeres. En relación con el egreso, Roqueñí señala que en ciencia política, las mujeres tienden a tener más éxito respecto de los hombres, es decir, que hay más mujeres que logran finalizar la carrera que hombres, lo que bien sostiene que la licenciatura en ciencia política en México se está "feminizando". 
La matrícula nos dice qué tan nacional es la carrera de ciencias políticas. Se observa que la UNAM (en todos sus campus) y la UACM concentran el 36\% de la matrícula total. Si separamos por área geográfica, en el Distrito Federal se concentra alrededor del 38\% de la matrícula nacional, seguido de otras universidades de estados relativamente cercanos al Distrito Federal, como la UAEM en el estado de México, y la BUAP en Puebla, que cuenta con dos licenciaturas, una propiamente en ciencias políticas en la Facultad de Derecho y Ciencias Sociales, y otra en administración pública y ciencias políticas en la Facultad de Administración. Con excepción del caso de la Universidad Autónoma de Baja California que creó la carrera en 1964, la mayor parte de la matrícula se concentra en estados con grandes universidades y con mayor población.

\section{Gráfico 1. Matrícula en Ciencia Política en México (ANUIES, 2012-2013)}

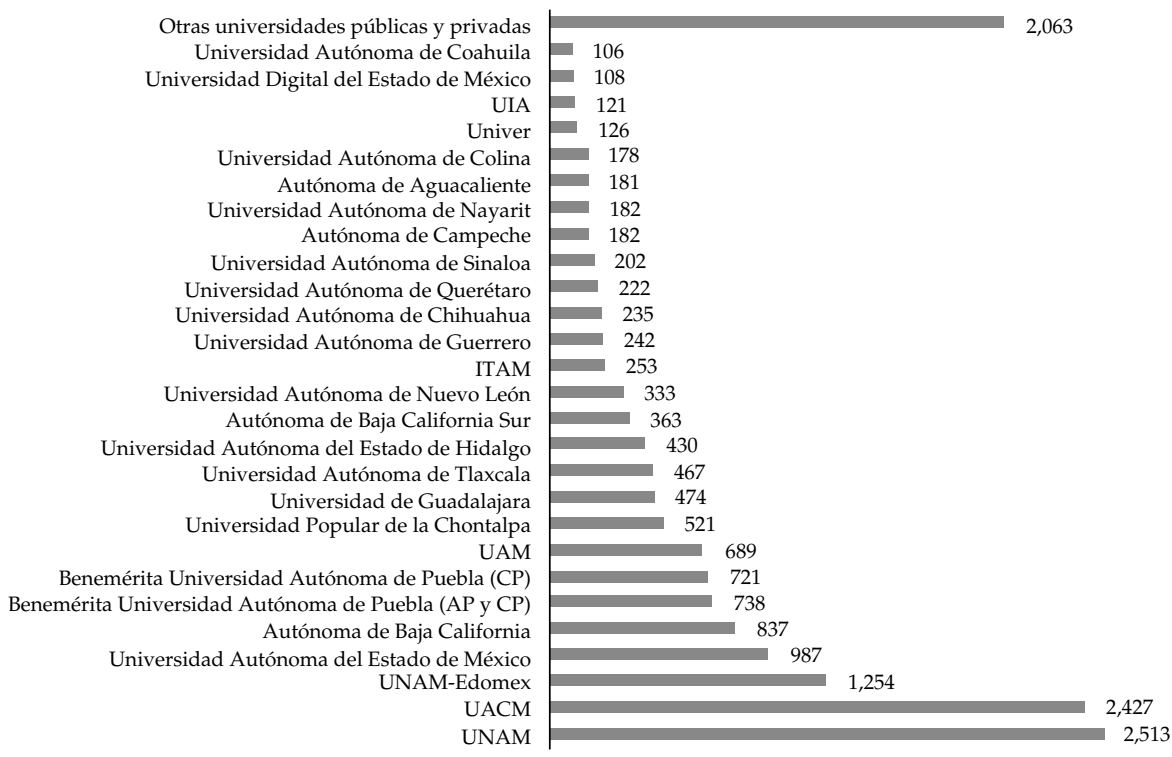

Fuente: Elaboración propia con datos del "Anuario estadístico 2013", Asociación Nacional de Universidades e Instituciones de Educación Superior, $2015<\mathrm{http}$ ://www.anuies.mx/content. php?varSectionID=166> [consultado en enero 2015]

La carrera de "ciencia política" -al singular- existe en muy pocas universidades: en las universidades públicas de Guanajuato y Nayarit, y en las universidades privadas ITAM, en la Universidad de las Américas y en el ITESM en diversos campus, que suman en conjunto una matrícula de 367 alumnos en 2013. Solo en algunas universidades públicas como la UAM-I y la BUAP, y en algunas privadas como la UPAEP y la Vasconcelos de Oaxaca -por mencionar-, ofrecen la carrera de "ciencias políticas" sin otro apéndice en su denominación. La variedad de carreras que se agrupan bajo el rótulo "ciencias políticas" -en plural- se puede observar en la información que ofrece la Secretaría de Educación Pública (SEP) en relación con las cédulas profesionales (Anexo. Gráfico A) 
que desde 1974 y hasta el 2010 había emitido; el 45\% de los egresados obtuvieron el título en "Ciencias Políticas y Administración Pública", seguido por "Administración Pública" (30,05\%), mientras que el resto son denominaciones que varían. Es significativo señalar que en algunas universidades, sobre todo privadas, la licenciatura en ciencia política se ofrezca con la doble titulación en Economía o en Derecho, y si bien son pocas, es muestra de la baja identificación disciplinar en algunas universidades. Un caso sobresaliente es la Universidad Autónoma de la Chontalpa en Tabasco, que tiene una matrícula superior a la de muchas otras universidades públicas (521). Esta es una universidad fundada desde el nivel municipal en una región relativamente aislada de los centros urbanos, la creación de una carrera con tales características muestra la visión que sobre el gobierno se tiene en la zona.

Para evaluar el nivel de empleo e ingreso monetario de quienes estudian estas carreras, el Instituto Mexicano de la Competitividad (IMCO) con información del 2013, ${ }^{3}$ señala que en México 86.942 personas han estudiado ciencias políticas a nivel de licenciatura, de los cuales el $32 \%$ son hombres y el $68 \%$ mujeres -lo que confirma la feminización de la matrícula-, el 58\% tiene más de 30 años y el resto es menor. En este grupo se incluyen las carreras de: ciencias sociales y política, derechos humanos, economía y política, estudios electorales, estudios políticos, estudios sobre la paz y conflictos, filosofía política, historia política y relaciones internacionales. Quienes han estudiado ciencias políticas son el 0,9\% del total de personas que cuentan con una licenciatura en México, y apenas ocupa el lugar 32 entre el número de carreras con mayor cantidad de personas, muy alejada de contabilidad, administración y derecho, que ocupan los tres primeros lugares de la lista.

Si bien los egresados de esta carrera tienen, relativamente, un alto nivel de ocupación con el $86,7 \%$ de empleo del total, este porcentaje está debajo de la media de las licenciaturas que es del $95 \%$, por lo que la carrera de ciencias políticas es una de las que tiene mayor tasa de desempleo, solo por debajo de sociología y antropología, aunque tiene un nivel de informalidad bajo, con un $24,2 \%$ siendo la media nacional del $59 \%$. La carrera de ciencias políticas no se encuentra entre las mejor pagadas, ocupando el lugar 35 de 62 carreras analizadas. Situación que cambia si se tiene un posgrado, pudiendo obtener más del doble de salario que solo con licenciatura, aunque con niveles similares a cualquier otra carrera en la misma situación.

Los principales sectores en los cuales se desempeñan quienes estudian ciencias políticas son las actividades gubernamentales y en organismos internacionales $(28,9 \%)$, los servicios educativos $(15,3 \%)$, la industria manufacturera $(10,5 \%)$, servicios profesionales $(7,4 \%)$ y servicios de apoyo a los negocios $(5,09 \%) .{ }^{4}$ Destaca que la mayoría ocupa una

3 La información que sistematizó el IMCO en "Compara carreras" < http://imco.org.mx/comparacarreras/\#!/ carrera/313> [consultado el 25 de enero de 2015] se basa en la Encuesta Nacional de Ocupación y Empleo del Instituto Nacional de Información Estadística y Geográfica (INEGI).

4 Esta distribución de áreas del desempeño coincide en cierta medida con los datos de seguimiento de egresados de ciencias políticas de la UNAM, que en 2011 señalaba que sus egresados se desempeñaban: $48 \%$ en el gobierno, $20 \%$ en partidos políticos, $17 \%$ en consultoría, $6 \%$ en la academia, $6 \%$ en periodismo, $2 \%$ en activismo y el $2 \%$ en empresas. 


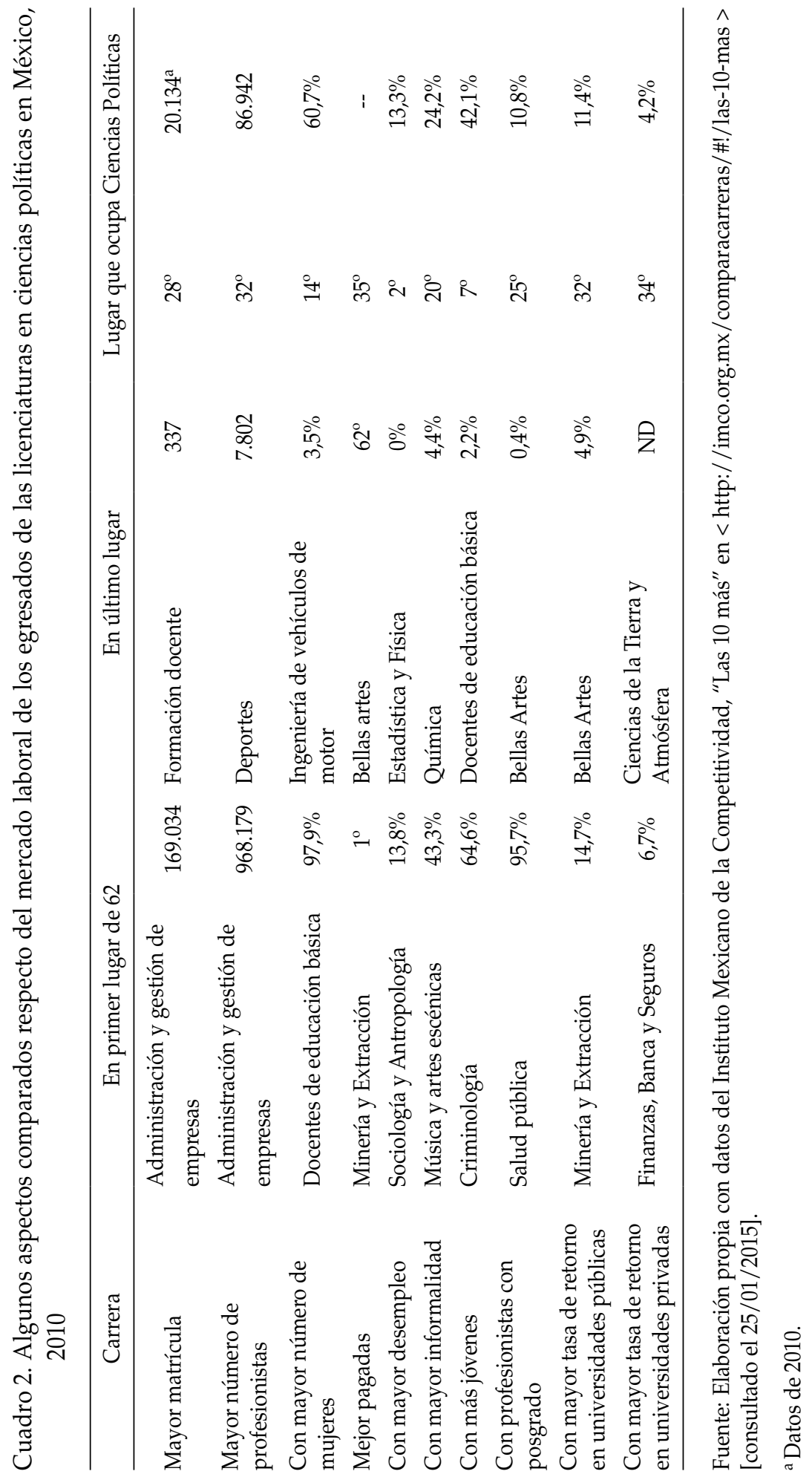


posición de subordinado (91\%) en tanto que apenas el 1,1\% es empleador, trabaja por cuenta propia y el 1,5\% no recibe pago por su desempeño.

¿Cuáles explicaciones para esta situación? Las actividades gubernamentales incluyen aquellas desde burócratas y hasta puestos de nivel directivo. Pero si tomamos en cuenta que el $91 \%$ es subordinado, ello significa que solo muy pocos politólogos se involucran en las grandes decisiones políticas dentro de la estructura de gobierno. De acuerdo con el politólogo e internacionalista mexicano José Luis Orozco (2012), la apertura del sistema político mexicano no trajo consigo un mercado de trabajo para los politólogos mexicanos, pues los políticos mexicanos, desde aquellos que obtienen un puesto en la administración pública municipal hasta los diputados y senadores, por lo general prefieren contratar a sus "amigos" antes que a un especialista que los asesore o asista en sus actividades. El panorama es más claro cuando nos adentramos un poco más en ciertas particularidades como las que ofrece la UNAM con datos de seguimiento de sus egresados (Apéndice. Gráfico B): un porcentaje significativo labora en partidos políticos, otros como consultor, y un porcentaje menor en el periodismo, el activismo político o trabaja en empresas. Es significativo que varios politólogos se involucren en la política, generalmente dominada por quienes estudiaron derecho, algo natural si se toma en cuenta que es la carrera con mayor número de egresados; según el Sistema de Información Legislativa (http:/ / sil.gobernacion.gob.mx/) en el periodo 2012-2015 en Cámara de Diputados, once miembros estudiaron ciencias políticas, mientras que en la de Senadores se contabilizan siete en el mismo periodo.

Ahora bien, en México existen diversos posgrados en Ciencias Sociales o Estudios Sociales, pero pocos en Ciencias Políticas o Ciencia Política (Cuadro 3). La mayoría se enfocan a la administración pública o a las políticas públicas, incorporando en su currículo materias de ciencia política. En cuanto a los doctorados, pocos mencionan la especialidad, y la especialización en ciencia política deriva más del proyecto de investigación que de la orientación del programa en sí.

De acuerdo con información del Consejo Nacional de Ciencia y Tecnología (Conacyt), la institución rectora de las políticas de investigación y calidad en el posgrado en México, en febrero de 2015 se contabilizan 14 programas de maestría en ciencias políticas o con especializaciones relativas, todas en universidades o centros de investigación públicas. Cinco son de reciente creación, y el resto tiene algún nivel de excelencia otorgado por el Conacyt debido a su permanencia, eficiencia terminal y mantenimiento de la calidad de su planta de profesores. El número de doctorados es menor, apenas nueve, uno de ellos en una universidad privada, tres son de reciente creación y apenas siete mantienen un nivel de excelencia, destacando solo dos que recibieron la categoría de "competencia internacional".

\section{LA INVESTIGACIÓN POLITOLÓGICA}

Gran parte de la vitalidad de la ciencia política se observa en quienes la cultivan e investigan, y en la calidad de su producción científica. México cuenta con el Sistema 
Cuadro 3. Posgrados en Ciencia Política en México en el Padrón de Excelencia del Conacyt

\begin{tabular}{|c|c|c|c|c|c|}
\hline Estado & Institución & Maestría & Nivel & Doctorado & Nivel \\
\hline \multirow[t]{2}{*}{ Puebla } & $\begin{array}{l}\text { Benemérita } \\
\text { Universidad } \\
\text { Autónoma de Puebla }\end{array}$ & $\begin{array}{l}\text { Opinión Pública } \\
\text { y Marketing } \\
\text { Político }\end{array}$ & 1 & $\begin{array}{l}\text { Ciencias de } \\
\text { Gobierno y } \\
\text { Política }\end{array}$ & 1 \\
\hline & & Ciencias Políticas & 3 & - & \\
\hline \multirow[t]{6}{*}{ Distrito Federal } & El Colegio de México & Ciencia Política & 3 & & \\
\hline & Flacso-México & - & - & $\begin{array}{l}\text { Ciencias } \\
\text { Sociales con } \\
\text { mención en } \\
\text { Ciencia Política }\end{array}$ & 4 \\
\hline & Instituto Mora & Sociología Política & 3 & - & - \\
\hline & $\begin{array}{l}\text { Universidad } \\
\text { Autónoma } \\
\text { Metropolitana }\end{array}$ & $\begin{array}{l}\text { Estudios Sociales } \\
\text { línea Procesos } \\
\text { Políticos }\end{array}$ & 4 & $\begin{array}{l}\text { Estudios } \\
\text { Sociales línea } \\
\text { Procesos } \\
\text { Políticos }\end{array}$ & 4 \\
\hline & $\begin{array}{l}\text { Universidad } \\
\text { Iberoamericana* }\end{array}$ & & & $\begin{array}{l}\text { Ciencias } \\
\text { Sociales y } \\
\text { Políticas }\end{array}$ & 3 \\
\hline & $\begin{array}{l}\text { Universidad Nacional } \\
\text { Autónoma de México }\end{array}$ & $\begin{array}{l}\text { Estudios Políticos } \\
\text { y Sociales }\end{array}$ & 3 & $\begin{array}{l}\text { Ciencias } \\
\text { Políticas y } \\
\text { Sociales }\end{array}$ & 3 \\
\hline Jalisco & $\begin{array}{l}\text { Universidad de } \\
\text { Guadalajara }\end{array}$ & Ciencia Política & 1 & $\begin{array}{l}\text { Ciencia } \\
\text { Política }\end{array}$ & 1 \\
\hline San Luis Potosí & $\begin{array}{l}\text { El Colegio de } \\
\text { San Luis }\end{array}$ & $\begin{array}{l}\text { Asuntos Políticos } \\
\text { y Políticas } \\
\text { Públicas }\end{array}$ & 2 & - & - \\
\hline Guanajuato & $\begin{array}{l}\text { Universidad de } \\
\text { Guanajuato }\end{array}$ & Análisis Político & 1 & $\begin{array}{l}\text { Estudios } \\
\text { Jurídicos, } \\
\text { Políticos y de } \\
\text { Gobierno }\end{array}$ & 1 \\
\hline Guerrero & $\begin{array}{l}\text { Universidad } \\
\text { Autónoma } \\
\text { de Guerrero }\end{array}$ & Ciencia Política & 1 & - & \\
\hline Michoacán & $\begin{array}{l}\text { Universidad } \\
\text { Michoacana de San } \\
\text { Nicolás de Hidalgo }\end{array}$ & $\begin{array}{l}\text { Derecho con } \\
\text { opción en Ciencia } \\
\text { Política }\end{array}$ & 2 & & \\
\hline Nuevo León & $\begin{array}{l}\text { Universidad } \\
\text { Autónoma de } \\
\text { Nuevo León }\end{array}$ & Ciencias Políticas & 2 & $\begin{array}{l}\text { Filosofía con } \\
\text { orientación } \\
\text { en Ciencias } \\
\text { Políticas }\end{array}$ & 2 \\
\hline
\end{tabular}




\begin{tabular}{|c|c|c|c|c|c|}
\hline Estado & Institución & Maestría & Nivel & Doctorado & Nivel \\
\hline Tamaulipas & $\begin{array}{l}\text { Universidad } \\
\text { Autónoma de } \\
\text { Tamaulipas }\end{array}$ & $\begin{array}{l}\text { Ciencia Política y } \\
\text { Administración } \\
\text { Pública }\end{array}$ & 1 & - & - \\
\hline Zacatecas & $\begin{array}{l}\text { Universidad } \\
\text { Autónoma de } \\
\text { Zacatecas }\end{array}$ & Ciencia Política & 2 & Ciencia Política & 2 \\
\hline
\end{tabular}

Fuente: Elaboración propia con datos del "Padrón del Programa Nacional de Posgrados de Calidad", CONACYT, <http://svrtmp.main.conacyt.mx/ConsultasPNPC/listar_padron.php> [consultado en febrero 2015].

Nivel: 1.-Reciente Creación; 2.- En desarrollo; 3.- Consolidado y; 4.- Competencia Internacional.

* Universidad privada.

Nacional de Investigadores (SNI), al cual se accede de manera voluntaria si se tiene un nivel de producción significativa que amerite obtener este reconocimiento. A enero de 2015 se encontraban registrados 550 investigadores (Cuadro 4) en el Área de Ciencias Políticas ${ }^{5}$ de los que la mayoría son hombres y apenas casi el 30\% son mujeres. Lo que contrasta con la feminización de la matrícula: muchas mujeres estudian ciencias políticas, pero pocas la cultivan. En relación con el nivel que obtienen en el SNI, la mayoría de los investigadores en ciencias políticas están en los niveles $\mathrm{C}$ y 1, es decir, que han mantenido al menos por poco más de cuatro años una producción científica relevante en su área, y quizá algunos mucho más. Apenas 148 mantienen un nivel 2 y 3 , lo que significa que coordinan grupos de investigación, publican libros como autores propios y sus artículos son publicados en revistas internacionales, son ampliamente citados, y sobre todo, participan en la formación de recursos de alto nivel (maestría y doctorado) en su área de estudios. Si bien los miembros de los niveles C y 1 también pueden desarrollar -y por lo general lo hacen- las mismas actividades, en los niveles

Cuadro 4. Nivel y género de los investigadores en ciencias políticas en México, 2015

\begin{tabular}{lrrrrrr}
\hline Nivel en el SNI & \multicolumn{1}{c}{ C } & \multicolumn{1}{c}{1} & \multicolumn{1}{c}{2} & \multicolumn{1}{c}{3} & Total & \multicolumn{1}{c}{$\%$} \\
\hline Hombres & 68 & 213 & 69 & 40 & 390 & 71 \\
Mujeres & 45 & 76 & 28 & 11 & 160 & 29 \\
Total N & 113 & 289 & 97 & 51 & 550 & 100 \\
& $20,5 \%$ & $52,54 \%$ & $17,6 \%$ & $10,7 \%$ & & \\
\hline
\end{tabular}

Fuente: Elaboración propia con datos de "Investigadores Vigentes Sistema Nacional de Investigadores", CONACYT <http://www.conacyt.gob.mx/images/SNI/DIRECTORIO_SNI_2015.xlsx> [consultado en febrero de 2015]. 
superiores se encuentran aquellos que han mantenido una producción constante y una línea de investigación consistente por un lapso de tiempo significativo.

Por otro lado, ¿en cuál disciplina se autoadscriben los politólogos mexicanos? Es decir, ¿cuáles son las áreas preferidas de investigación? (Gráfico 2) Las subdisciplinas y las especialidades son variadas, y van desde el comportamiento político, los conflictos sociales, las elecciones, la cooperación internacional, pasando por el estudio de los partidos, las relaciones entre los poderes, las políticas de educación hasta el liderazgo político. Destaca que gran parte de los investigadores se dedique a temas de las relaciones internacionales y la administración pública, y apenas unos cuantos a la política teórica y el estudio de las ideologías políticas, lo que muestra que el énfasis de la investigación politológica de los últimos años se está centrando en aspectos relativos a las políticas públicas y las relaciones de poder a nivel internacional.

Gráfico 2. Principales áreas de investigación de los politólogos en México, 2015

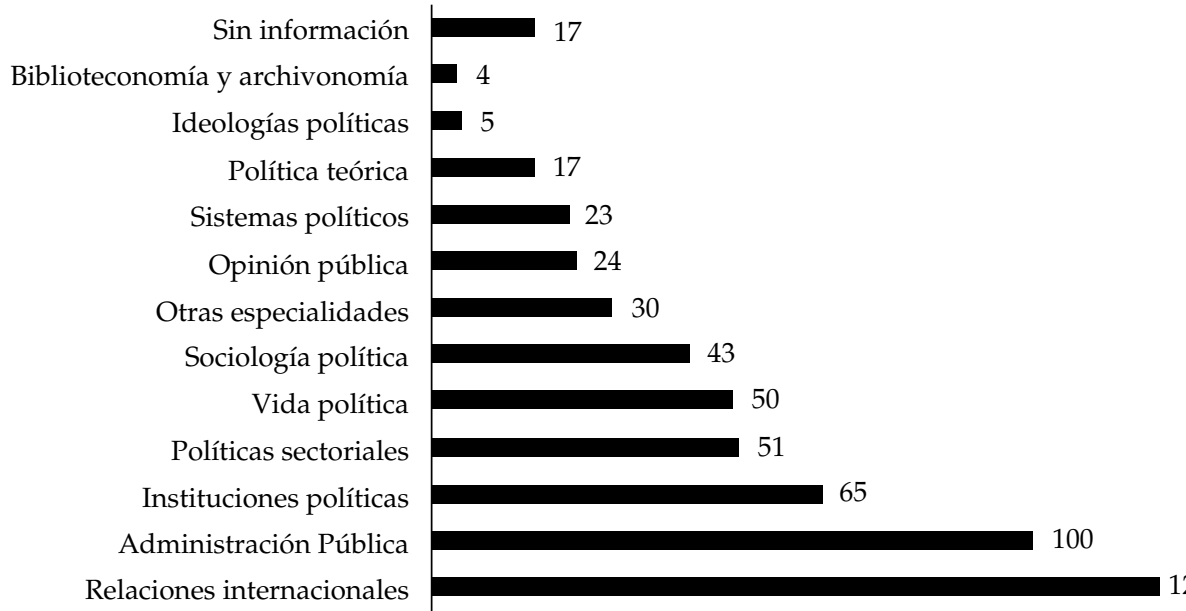

Fuente: Elaboración propia con datos de "Investigadores Vigentes Sistema Nacional de Investigadores", CONACYT <http://www.conacyt.gob.mx/images/SNI/DIRECTORIO_SNI_2015.xlsx> [consultado en febrero de 2015].

Ahora bien ¿en dónde se desarrolla la investigación politológica? La mayoría de quienes cultivan e investigan en torno a las ciencias políticas están en el Distrito Federal (Gráfico 3), no obstante es probable que en los próximos años esta concentración desaparezca en tanto que existen una serie de incentivos salariales para descentralizar la investigación en el país.

En cuanto a las universidades y centros de investigación, en cuatro se concentran prácticamente el $40 \%$ de los investigadores en ciencias políticas, y aunque ello no significa que todos estén en el Distrito Federal, con excepción de El Colegio de México, la UNAM, la UAM y el CIDE tienen sedes en otros estados del país. Pero sí concentran un porcentaje 
Gráfico 3. Distribución territorial de los politólogos (\% investigadores en el Conacyt) en México,

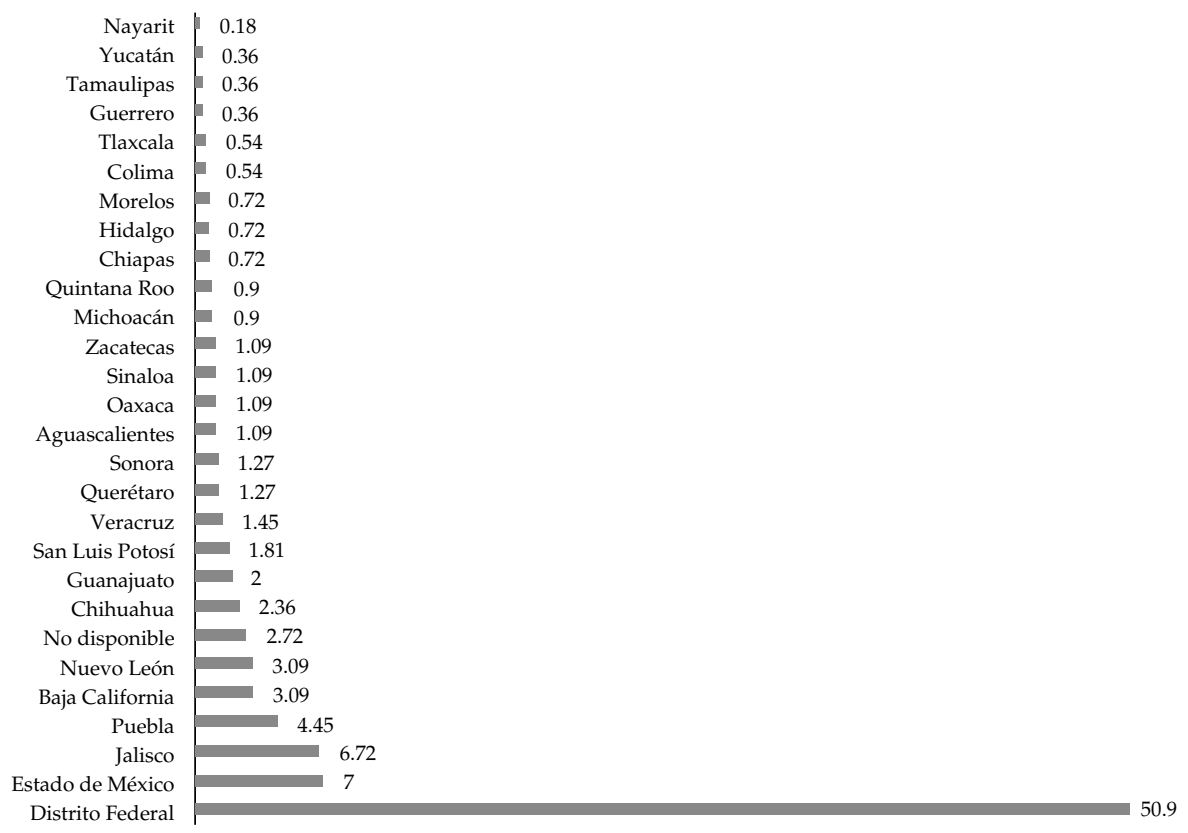

Fuente: Elaboración propia con datos de "Investigadores Vigentes Sistema Nacional de Investigadores", CONACYT <http://www.conacyt.gob.mx/images/SNI/DIRECTORIO_SNI_2015.xlsx> [cons ultado en febrero de 2015].

importante de los politólogos en México. Esta situación se explica porque si bien la carrera se ha difundido en muchas universidades del resto del país, la investigación es todavía una actividad poco comprendida en toda su amplitud en las universidades estatales, o más aún, los profesores tienen que desarrollar actividades de docencia -a veces con muchas horas-, de gestión y de difusión, lo que deja poco tiempo a la investigación, ello explicaría en parte esta concentración en cuatro instituciones: El Colegio de México y el CIDE propiamente dedicados preponderantemente a la investigación, y dos, la UNAM y la UAM, que por su tamaño pueden concentrar más investigadores. Esto es lo que explica la existencia de "archipiélagos" -endogamia y autorreferencial- y los "enclaves" -ajenos a la realidad nacional y con poco o nulo impacto de la investigación- en la ciencia política mexicana (Aguilar, 2009), que por fortuna y a juicio de este autor está cambiando, quizá lentamente, pero el proceso está en marcha.

Las revistas científicas son un indicador importante de la producción de los investigadores y estudiosos de una disciplina, pero no son el único vehículo, ni necesariamente el de mayor impacto, lo que sí es cierto, es que dado que hoy por hoy se facilita su acceso por medio de la internet, se cuenta con mayor y mejor información respecto de su difusión. Los libros, de carácter científico por supuesto, tienen un valor superior en tanto que por lo regular son resultado de ampliar precisamente los argumentos y resultados de una 
Gráfico 4. Principales universidades y centros de investigación con politólogosinvestigadores en el SNI-Conacyt, 2015

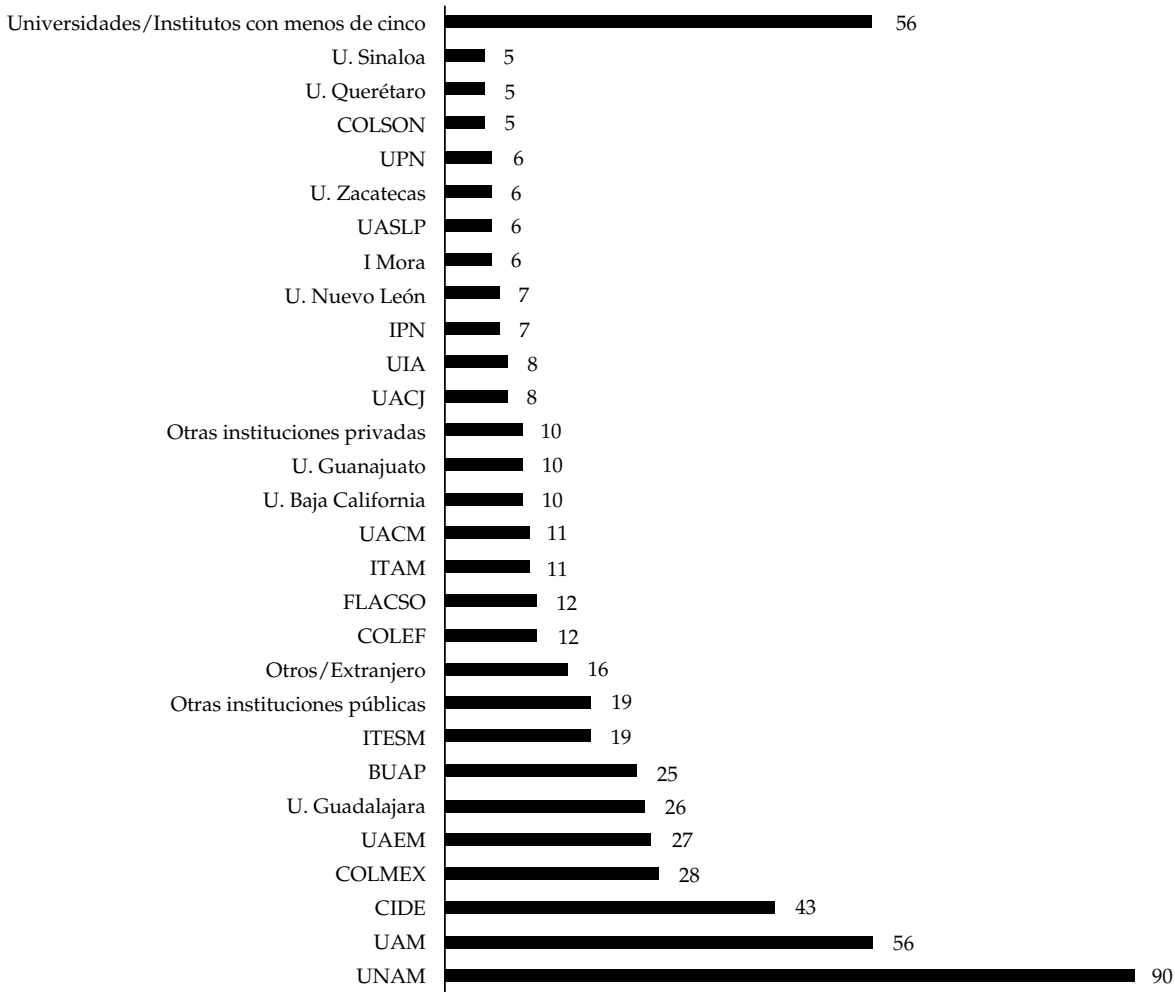

Fuente: Elaboración propia con datos de "Investigadores Vigentes Sistema Nacional de Investigadores", CONACYT < http://www.conacyt.gob.mx/images/SNI/DIRECTORIO_SNI_2015.xlsx> [consultado en febrero de 2015].

investigación escrita en un artículo académico, además de que agregan las reflexiones que surgen de las críticas de los primeros resultados presentados. Más aún, respecto de los libros, las revistas académicas pueden generar sesgos metodológicos y temáticos, y si bien fomentan la calidad en la investigación, al mismo tiempo reducen la libertad y por lo tanto la innovación (vid. Gould, 2013).

Empero, y con estas precauciones, debemos tomar en cuenta que las revistas científicas son el vehículo natural de la publicidad de las investigaciones que se desarrollan por lo general en las universidades y los centros de investigación, y son al mismo tiempo el soporte de tales publicaciones. Tomando como base el sistema "Red de Revistas Científicas de América Latina y el Caribe, España y Portugal" (Redalyc), en México se publican alrededor de 31 revistas (Cuadro 5) dedicadas a las ciencias políticas (así, en plural) entre las que se encuentran aquellas más enfocadas propiamente a la ciencia política (en singular) hasta las que amplían su rango en la administración pública, las relaciones internacionales, la sociología política, los estudios regionales, las migraciones, 
entre otras temáticas. De estas, solo dos se publican en universidades privadas, mientras que el resto son producto de instituciones públicas. La mayoría (21) se publican en instituciones que tienen su sede principal en el Distrito Federal, mientras que apenas 10 revistas se publican en otros estados del país, siendo la Universidad Autónoma del Estado de México -muy cercana geográficamente a la Ciudad de México- la que tiene más revistas en el área fuera de la capital del país.

La integración a ciertos índices ofrece visibilidad y mayor difusión a los resultados de investigación, al tiempo que direcciona a las revistas a mantener ciertos estándares de calidad que hacen más conveniente publicar en unas revistas que en otras. La lógica es que a mayor número de índices mayor difusión, pero algunos índices resultan más relevantes que otros. De las 31 revistas en Redalyc, solo 20 están dentro del Conacyt, y apenas 18 se encuentran en Scielo-México. Igualmente es importante que trasciendan la región. De las revistas en "Ciencia Política" que incluye el Social Sciences Citation Index (SSCI), solo aparecen seis revistas Iberoamericanas, ${ }^{6}$ cinco se publican en español, cuatro son latinoamericanas y solo Política y Gobierno se publica en México, y es la única que aparece en el Journal Citation Report, ${ }^{7}$ en el lugar 141 de 157, con un factor de impacto de 0,158, donde la American Political Science Review ocupa el primer lugar con un factor de 3,844. Empero, la lista se extiende a seis revistas mexicanas en el SSCI si se amplía el rango a "Ciencias Sociales". ${ }^{8}$ Empero no son las mismas que se incluyen en el International Political Science Abstracts, índice de mayor consulta entre los politólogos a nivel mundial. Apenas cinco aparecen en el Journal Citation Report, las cuales pueden considerarse como las revistas más importantes de ciencia política en México. Tomando el conjunto de revistas consideradas, se confirma la aseveración de que la disciplina se sigue entendiendo en plural (ciencias políticas) y poco todavía en singular (ciencia política).

Las bases más utilizadas en lengua español (SCielo y Redalyc) todavía no cuentan con información suficiente para valorar el factor de impacto de las publicaciones, no tanto por los índices, sino por la dificultad de la gestión de las revistas dentro de las propias universidades, de allí que muchas publicaciones a veces no mantienen la periodicidad.

\section{LAS ASOCIACIONES DE POLITÓLOGOS}

Finalmente es necesario referirnos a las asociaciones que agrupan a los politólogos en México. La atención resulta pertinente pues hasta hace apenas 3-4 años no existía ninguna asociación de politólogos en México, que es el país latinoamericano con un alto grado de institucionalización de la disciplina si la observamos comparativamente (vid. Barrientos, 2012). La desorganización que padeció la ciencia política mexicana se debía en gran parte a que las asociaciones servían más para ponderar personajes afines

6 Revista Brasileira de Politica Internacional (Brasil), Revista de Ciencia Política (Chile), Revista de Estudios Políticos, Historia y Política (España), Revista del CLAD Reforma y Democracia (Venezuela) y Política y Gobierno (México). Todas estas también son revistas JCR

$<$ jcr.incites.thomsonreuters.com>

Estas son Andamios, Gestión y Política Pública, Perfiles Latinoamericanos, Convergencia y Espiral. 
Cuadro 5. Revistas de Ciencia Política, Relaciones Internacionales y Multidisciplinarias (Ciencias Sociales) en México (Base Redalyc, 2015)

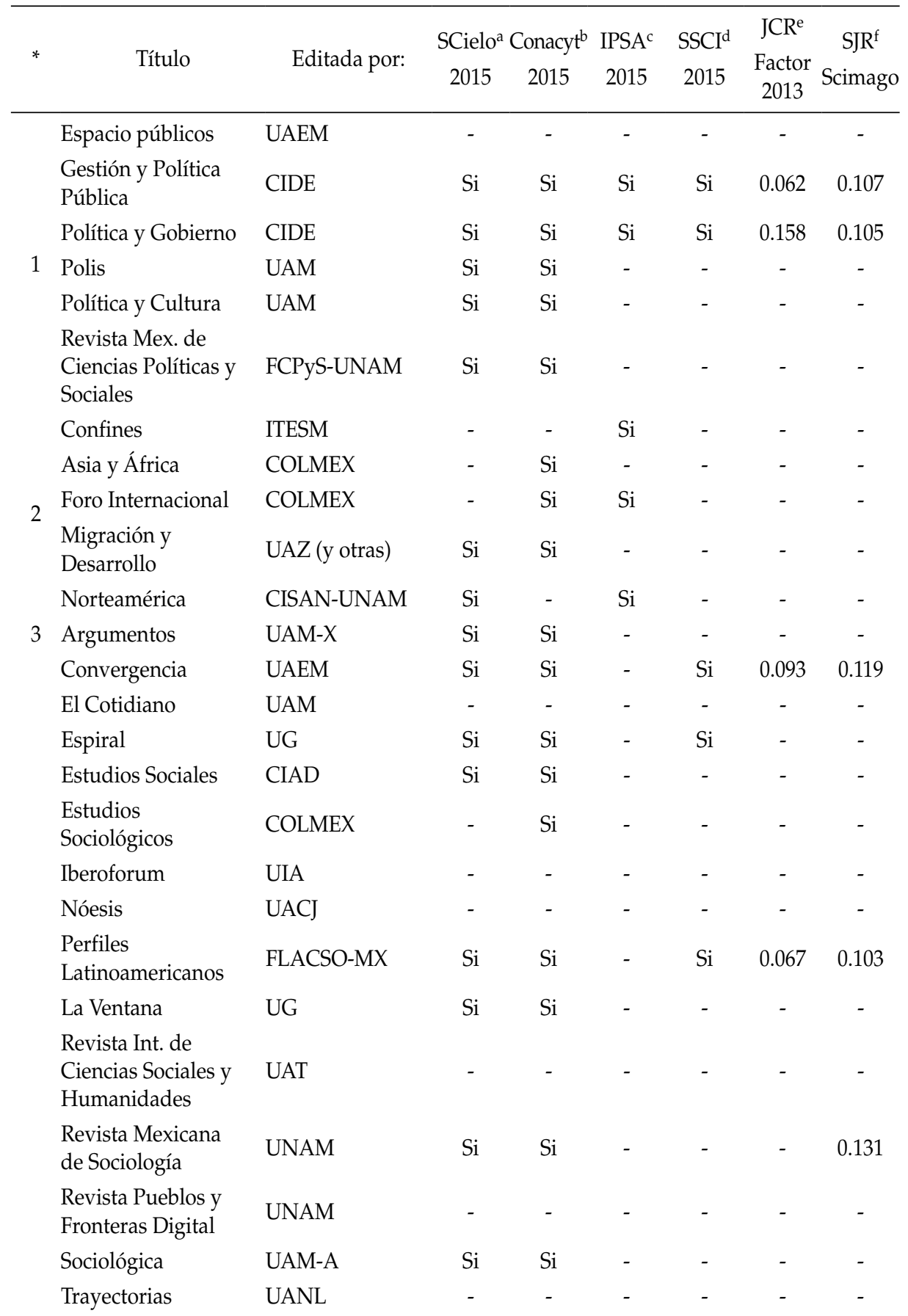




\begin{tabular}{|c|c|c|c|c|c|c|c|c|}
\hline * & Título & Editada por: & $\begin{array}{c}\text { SCielo }^{\mathrm{a}} \\
2015\end{array}$ & $\begin{array}{l}\text { Conacyt } \\
2015\end{array}$ & $\begin{array}{l}\text { IPSA }^{c} \\
2015\end{array}$ & $\begin{array}{c}\mathrm{SSCl}^{\mathrm{d}} \\
2015\end{array}$ & $\begin{array}{l}\text { JCR }^{\mathrm{e}} \\
\text { Factor } \\
2013\end{array}$ & $\begin{array}{c}\text { SJR }^{f} \\
\text { Scimago }\end{array}$ \\
\hline \multirow{5}{*}{4} & Andamios & UACM & $\mathrm{Si}$ & $\mathrm{Si}$ & $\mathrm{Si}$ & $\mathrm{Si}$ & 0.019 & 0.111 \\
\hline & Ciencia Ergo Sum & UAEM & - & - & - & - & - & - \\
\hline & $\begin{array}{l}\text { Contribuciones desde } \\
\text { Coatepec }\end{array}$ & UAEM & - & - & - & - & - & - \\
\hline & Latinoamérica & UNAM & $\mathrm{Si}$ & $\mathrm{Si}$ & - & - & - & - \\
\hline & Nova Scientia & ULSA & $\mathrm{Si}$ & $\mathrm{Si}$ & - & - & - & - \\
\hline$\sum$ & 31 & 31 & 18 & 20 & 6 & 6 & 5 & 6 \\
\hline
\end{tabular}

Fuente: Elaboración propia.

* Redalyc clasifica estas revistas en las disciplinas Política (agrupada en el 1), Relaciones Internacionales (2), Sociología (3) y Estudios Multidisciplinarios (4). En ésta última solo se agregaron las revistas que se dedican a las ciencias sociales, en: <http:/ / www.redalyc.org/coleccionHome.oa>

a Scielo México, en: <http://www.scielo.org.mx/scielo.php?script=sci_subject\&lng=es\&nrm=iso>

b Índice de Revistas Mexicanas de Investigación Científica y Tecnológica, en: <http:/ /www. conacyt.mx/index.php/comunicacion/indice-de-revistas-mexicanas-de-investigacion/category/ listado-completo>

c IPSA: International Political Science Abstracts, en: <http://www.ebscohost.com/ACADEMIC/ international-political-science-abstracts>

d SSCI: Social Science Citation Index, en: <http://ip-science.thomsonreuters.com/cgi-bin/jrnlst/ jloptions.cgi?PC=SS>

e JCR: Journal Citation Index, en: < http://thomsonreuters.com/journal-citation-reports/ >

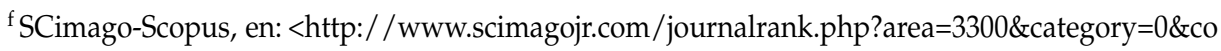
untry $=$ MX\&year $=2013 \&$ order $=$ sjr\&min $=0 \&$ min_type $=c d>$

al partido hegemónico (PRI) que para representar a los estudiosos y practicantes de la disciplina. Si bien es cierto que solo en algunos momentos el Colegio Nacional de Ciencias Políticas y Administración Pública llegó a organizar en 1996 y en 2001 dos congresos internacionales que congregaron a gran parte de la comunidad politológica del país, esto fue más bien producto de destacadas iniciativas personales que de un interés gremial. Por ello la mayoría de los politólogos se organizaron en torno a subdisciplinas, como las relaciones internacionales, la administración pública o las ciencias de la comunicación, y en gran parte se sintieron obligados a monotematizarse, al menos en apariencia.

Durante varios años, desde 1998, gran parte de los politólogos se congregaron alrededor de la Sociedad Mexicana de Estudios Electorales, otros decidieron crear una asociación de estudios parlamentarios en 2001, mientras que aquellos provenientes de carreras más profesionalizantes como relaciones internacionales o administración pública contaban con asociaciones que desde hacía años funcionaban bajo modalidades diferentes. Empero, según la apreciación de Vidal (2013: 101), varias de las organizaciones respondían en mayor 
Cuadro 6. Organizaciones que agrupan a estudiosos de la ciencia política y disciplinas afines

\begin{tabular}{llc}
\hline \multicolumn{1}{c}{ Siglas } & \multicolumn{1}{c}{ Nombre } & \multicolumn{1}{c}{ Año de fundación } \\
\hline AMECIP & Asociación Mexicana de Ciencias Políticas A.C. & 2012 \\
COMICIP & Consejo Mexicano de Investigación en Ciencia Política & 2012 \\
& A.C. & $1998^{\mathrm{a}}$ \\
SOMEE & Sociedad Mexicana de Estudios Electorales A.C. & $1967^{\mathrm{b}}$ \\
AMEI & Asociación Mexicana de Estudios Internacionales A.C. & 2001 \\
AMEP & Asociación Mexicana de Estudios Parlamentarios A.C. & 1955 \\
INAP ${ }^{\text {d }}$ & Instituto Nacional de Administración Pública A.C. & 1994 \\
ANECPAP & Asociación Nacional de Estudiantes de Ciencia Política & 1979 \\
& y Administración Pública & \\
AMIC ${ }^{\text {d }}$ & Asociación Mexicana de Investigadores de la & 1974 \\
& Comunicación & \\
CNCPYAP e & Colegio Nacional de Ciencias Políticas y Administración & \\
\hline
\end{tabular}

Fuente: Elaboración propia.

a Sus orígenes están en 1986 como grupo de investigación dentro del Consejo Mexicano de Ciencias Sociales (COMECSO).

${ }^{\mathrm{b}}$ Originalmente se llamó Instituto Mexicano de Estudios Internacionales, cambiando a AMEI en 1982.

${ }^{\mathrm{c}}$ Agrupa solo a estudiantes de licenciatura.

${ }^{\mathrm{d}}$ Agrupa tanto a académicos como profesionales de la disciplina.

e Si bien existe legalmente, desde hace más de 15 años no funciona con regularidad ni reúne a los estudiosos de las disciplinas.

medida a los estímulos burocráticos de las instituciones del Estado, y en menor medida a las inercias promovidas por los intereses del gremio de politólogos independientemente de la subdisciplina a la que se adscribieran. La situación cambió en el tercer lustro cuando se crean dos organizaciones con objetivos similares, la AMECIP y el COMICIP, que agrupan a politólogos de diversas universidades. La primera ha organizado dos grandes congresos con especialistas internacionales y fundado una revista, mientras que la segunda ha tendido a organizar eventos focalizados. En 2015 podemos decir que las asociaciones que agrupan a los politólogos en sus diversas adscripciones disciplinares, funcionan bien y con regularidad, promueven encuentros y publicaciones con relativo éxito. Empero son también la muestra de una fragmentación, que para algunos es un lastre mientras que para otros, como quien escribe, es una forma natural de promover el asociacionismo sin necesidad de cobijarse bajo un único gran manto gremial. 


\section{CONCLUSIONES}

La ciencia política en México se ha institucionalizado, y sigue creciendo, no sin dilemas como cualquier otra ciencia que se desarrolla en otras latitudes. Los datos que se han presentado muestran que no obstante el tamaño del país, la ciencia política no se ha desarrollado en la medida del potencial que tiene gracias a las bases institucionales en la cuales se desenvuelve y la vecindad con las universidades de Estados Unidos, solo por mencionar algunos aspectos. Si bien los números en relación con la matrícula muestran que puede crecer, hay que mencionar que esta ciencia y sus subdisciplinas no pertenecen al grupo de las carreras masivas, y lo mismo a nivel del posgrado, un crecimiento exponencial de la matrícula en ambos niveles quizá pueda demeritar su calidad. Por ello debe continuar su consolidación por la vía de la investigación, y aún este camino tiene sus propios dilemas.

La ciencia política en México se desarrolla en gran medida en instituciones públicas, y éstas se dividen en universidades y centros de investigación. Es sobre todo en las universidades donde los académicos dedicados al estudio de la política por lo regular deben concentrar gran parte de su tiempo en la docencia y menos a la investigación y la difusión. A diferencia de los centros de investigación, en las universidades -públicas, principalmente- los cultores de la disciplina deben diversificar sus tareas más allá de la investigación científica, incluso, debe decirse que en muchas universidades estatales, donde la carrera es todavía nueva, el desarrollo de la investigación no está socialmente valorado, pues incluso dentro de las mismas universidades no se pondera la relevancia de esta actividad. De allí que en algunos estudios (e.g. Altman, 2012; Salazar-Elena y Rivera, 2011) al sesgar en la investigación y las publicaciones el desarrollo de la ciencia política mexicana, el panorama de la politología mexicana aparezca centrado en apenas unas cuantas instituciones. Como se ha visto en realidad el panorama es más amplio y complejo.

Aún considerando solo la investigación y sus resultados, la ciencia política mexicana todavía no logra sobresalir a nivel internacional a pesar de su crecimiento. ${ }^{9}$ Para algunos podría parecer que no es necesario, que la ciencia política mexicana está consolidada porque se ocupa hoy más que en otras décadas de los temas propiamente del ejercicio y la distribución del poder en el contexto democrático en todas la latitudes; para otros muestra una ciencia parroquialista, ${ }^{10}$ porque no "viaja" (en sentido sartoriano), sus investigaciones no son relevantes más allá de las fronteras y porque no se han adoptado los cánones metodológicos de la politología mundial (si es que existe). Lo paradójico

9 En "A Global Ranking of Political Science Departments" (Hix, 2004) no aparece ninguna institución latinoamericana dedicada a la ciencia política. Y aunque el sesgo lingüístico, a decir del autor, era necesario debido a que el inglés es la lingua franca de la ciencia, apenas aparece un centro de investigación español, lo que denota cierto desarrollo euroamericano de la disciplina.

10 Al respecto Andreas Schedler señala: “[...] en términos generales, la ciencia política mexicana sigue siendo muy parroquial y «rollera». Le hace falta una mayor presencia de aquella ciencia política que critica Sartori con tanta elocuencia. Le hace falta más investigación empírica y sistemática, más generación de datos, más estadística y matemática, mayor atención a los cánones de observación e inferencia, mayor vinculación con la literatura comparada" Vid. Ortiz y Pérez, 2009:184 
es que la información que sirve de base en este texto para analizar el estado actual de la disciplina en México podría confirmar una y otra postura. Lo que en estricto sentido significa que la ciencia política mexicana es amplia y plural, tanto en los temas como en los métodos.

Resulta paradójico que no obstante el avance de la ciencia política en México, se acuse que la ciencia política se ha alejado de la filosofía y la teoría políticas, admitiendo acríticamente (cfr. Camou, 2009) una tesis controversial lanzada por Giovanni Sartori (2004) como si este alejamiento fuera un divorcio o separación irreconciliable. Esta es una lectura equivocada, o más bien apenas un señalamiento antes que una demostración (Suárez-Íñiguez, 2014b: 7) por al menos dos razones: en el siglo XXI sería imposible una ciencia política sin teoría ni filosofía política, por muy alejada que se encuentre siempre será necesario apuntar hacia una generalización que se conecte con una teoría y que esta a su vez refuerce su poder explicativo, o caso contrario, que un análisis empírico refute con éxito una generalización deductiva. Pero también es cierto que la ciencia es un lenguaje que se diferencia de la filosofía: requiere método y técnicas de comprobación empírica que confirmen o refuten sus generalizaciones. La ciencia no es -en principiodeducción y sobre todo no es especulación. Y ello deben considerarlo sobre todo los jóvenes que apenas se sumergen en el estudio de la ciencia política, una disciplina propia de nuestra época, vibrante y con futuro.

\section{ANEXOS}

Gráfico A.Cédulas de Ciencias Políticas ante la SEP, por año, valores no acumulados (1970-2010)

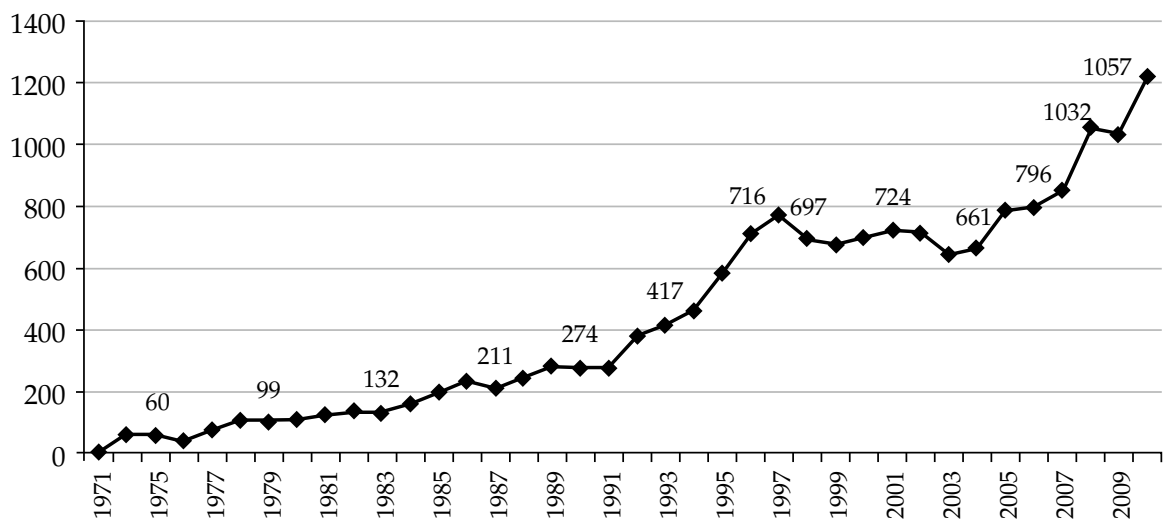




\section{Gráfico B. Ocupacional laboral de egresados de Ciencia Política de la UNAM}

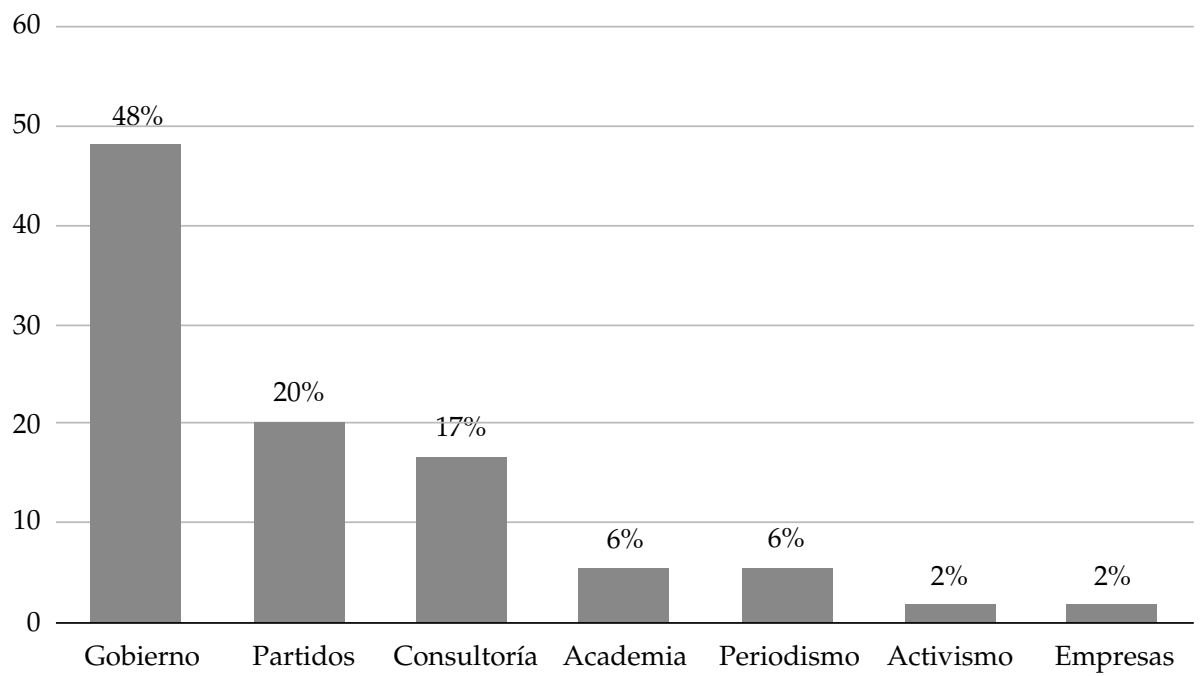

\section{REFERENCIAS}

Acosta Silva, Adrián. 2009. “La política en México: ideas, anteojos y cristales". Andamios 6 (11): 101-126. Aguiar Aguilar, Azul A. 2012. "The Institutional Change of the Public Prosecutor Office. The cases of Mexico, Chile and Brazil". Mexican Law Review IV (2): 261-290.

Aguilar Rivera, José Antonio. 2009. “El enclave y el incendio", Nexos, <http:/ /www.nexos.com.mx/?p=12852> [consultado el 03/03/2015]

Alarcón Olguín, Víctor. 2012a. La ciencia política en México. Trayectorias y retos de su enseñanza. México: Torres y Asociados/AMECIP.

Alarcón Olguín, Víctor. 2012b. "La Ciencia Política mexicana. Reflexiones sobre su pasado, presente y porvenir". Política. Revista de Ciencia Política 50 (1): 31-57.

Altman, David. 2012. "Where is Knowledge Generated? On the Productivity and Impact of Political Science Departments in Latin America". European Political Science 11 (1): 71-87

Arrieta Cisneros, Lorenzo. 2012. "El estudio sobre el sindicalismo y corporativismo en México". En La ciencia política en México hoy ¿qué sabemos?, Francisco Reveles (coord.), 267-292. México: FCPySUNAM, Plaza y Valdés.

Barrientos del Monte, Fernando. 2012. "La institucionalización de la ciencia política en América Latina”. En La ciencia política en México hoy ¿qué sabemos?, Francisco Reveles (coord.), 21-48. México: FCPySUNAM, Plaza y Valdés.

Camou, Antonio. 2009. “Quo Vadis Sartori. Ciencia política y políticas públicas en el marco de una polémica". Andamios 6 (11): 11-40.

Camp, Roderic Ai. 2012. Metamorfosis del liderazgo en el México democrático. México: FCE.

Caramani, Daniele. 2008. Comparative politics. Oxford: Oxford University Press.

Córdova, Arnaldo. 1973. La ideología de la Revolución Mexicana. México: Ediciones Era-IIS/UNAM.

Cortés Moreno, Jorge David; José Ramón López Rubí. 2010 y 2013. Cartas a los estudiantes de ciencia política. Vol. 1 y 2. México: BUAP-Miguel Ángel Porrúa.

Figueroa Franco, Marcela. 2012. “La profesión de politólogo. Una visión desde los planes de estudio". En La Ciencia Politica en México hoy: ¿qué sabemos? Francisco Reveles Vázquez (coord.), 79-102. México: UNAM-Plaza y Valdés. 
Flores Mariscal, J. R. Joel. 2012. “Los estudios sobre la Ciencia Política en México: una ventana al desarrollo de la disciplina". En La Ciencia Política en México hoy: ¿qué sabemos? Francisco Reveles Vázquez (coord.), 103-156. México: UNAM-Plaza y Valdés,

Furtak, Robert K. 1974. El Partido de la Revolución y la estabilidad política en México. México: UNAM.

Friedrichs, Robert. 2001 [original 1970]. Sociología de la sociología. Buenos Aires: Amorrortu.

Gould, Thomas H.P. 2013. Do We Still Peer Revieww? Plymouth, UK: The Sacrecrow Press.

Gómez Valle, José de Jesús. 2011. "El estudio de la ciencia política en Jalisco. La creación de la facultad de estudios políticos, internacionales y de gobierno de la Universidad de Guadalajara". Estudios Sociales 8: 227-239.

Gutiérrez Márquez, Enrique. 2014. “Algunas pinceladas que explican el desarrollo de las ciencias políticas en México". IberoAmericana 14 (56): 175-180.

Hirst, Paul. 2003. “The Future of Political Studies". European Political Science 3 (1): 47-59.

Hix, Simon. 2004a. "A Global Ranking of Political Science Departments". Political Studies Review 2 (3): 293-313.

Hix, Simon. 2004b. "European Universities in a Global Ranking of Political Science Departments". European Political Science 3 (2): 5-23.

Lujambio, Alonso. 1999. "Entre el pasado y el futuro: la ciencia política y el poder legislativo en México". En La ciencia política en México, Mauricio Merino (coord.). México: FCE-CNA, 75-92.

Orozco, José Luis. 2012. "Ciencias Políticas en México, profesión marcada por `amiguismos'", entrevista. Vanguardia. 24/10/2012, <http://www.vanguardia.com.mx/cienciaspoliticasenmexicoprofesionm arcadapor\%60amiguismos-1402438.html>

Patrón Sánchez, Fernando. 2014. "Los estudios legislativos en México: una revisión de su evolución, temas y ámbitos de desarrollo". Revista Mexicana de Análisis Político y Administración Pública III (2): 11-36.

Rivera, Mauricio; Salazar-Elena, Rodrigo. 2011. "El estado de la ciencia política en Méxic. Un retrato empírico". Política y Gobierno XVIII (1): 73-108.

Roqueñí Ibarguengoytia, María del Carmen. 2014. "Feminización de la Licenciatura en Ciencia Política en México. ¿Igualdad de oportunidades o inclusión desigual?". Estudios Políticos 32: 153-173.

Suárez-Iñiguez, Enrique. 2014a. "El largo camino hacia la autonomía y la institucionalizados de la ciencia política, en México y en el mundo". Estudios Políticos 32: 165-183.

Suárez-Íñiguez, Enrique. 2014b. Las sinrazones. Ciencia política a la norteamericana. México: Miguel Ángel Porrúa.

Loaeza, Soledad. 2005. "La ciencia política: el pulso del cambio mexicano". Revista de Ciencia Política 25 (1): 192-203.

Meyer, Lorenzo y Manuel Camacho. 1979. "La ciencia política en México. Estado actual y perspectivas". En V.V.A.A. Ciencias sociales en México. Desarrollo y perspectiva. México: El Colegio de México.

Ortiz Leroux, Sergio y Pérez Vega, Moisés. 2009. "La ciencia política a examen. Trayectoria, debates e identidad. Entrevista a Andreas Schedler, Francisco Valdés Ugalde y Víctor Alarcón Olguín". Andamios 6 (11): 151-191.

Sartori, Giovanni. 2004. "Where is Political Science Going?". Political Science and Politics I (04): 785-787.

Sínger Sochet, Martha. 2013. "Índice de Autores de la Revista Estudios Políticos 1975-2012". Estudios Políticos 29: 1-104.

Somit, Albert y Joseph Tanenhaus. 1964. American Political Science. A Profile of a Discipline. New York: Atherton Press.

Stoker, Gerry. 1995. "Introducción". En Teoría y métodos de la ciencia política, D. Marsh y G. Stoker (eds.). Madrid: Alianza, 15-29.

Vázquez, Rodolfo (Coord.). 2012. Corte, jueces y política. México: Fontamara-Nexos.

Vidal de la Rosa, Godofredo. 2013. Ensayos sobre la ciencia política en México y Latinoamérica. México: UAM-A. Zamitiz Gamboa, Héctor. 1999. "Origen y desarrollo de la ciencia política. Temas y problemas". Convergencia 20: 89-122. 
Fernando Barrientos del Monte es Doctor en Ciencia Política con especialización en Política Comparada por la Universidad de Florencia y el Istituto Italiano di Science Umane. Es miembro del Sistema Nacional de Investigadores del Conacyt (México). Es autor de los libros Buscando una identidad. Breve historia de la Ciencia Política en América Latina (México: Fontamara, 2014) y de Gestión electoral comparada y confianza en las elecciones en América Latina (México: INAP, 2011). Es Profesor-Investigador de Tiempo Completo, Director del Departamento de Estudios Políticos, y Editor Responsable de la Revista Mexicana de Análisis Político y Administración Pública (REMAP) en la División de Derecho, Política y Gobierno de la Universidad de Guanajuato, México.

E-mail: fbarrienmx@gmail.com 